\title{
BMJ Open Effect of critical illness insurance on the medical expenditures of rural patients in China: an interrupted time series study for universal health insurance coverage
}

\author{
Zhengdong Zhong, ${ }^{1}$ Junnan Jiang (D) , ${ }^{1}$ Shanquan Chen, ${ }^{2} \mathrm{Lu} \mathrm{Li,}{ }^{1} \mathrm{Li}$ Xiang ${ }^{1}$
}

To cite: Zhong Z, Jiang J, Chen S, et al. Effect of critical illness insurance on the medical expenditures of rural patients in China: an interrupted time series study for universal health insurance coverage. BMJ Open 2021;11:e036858. doi:10.1136/ bmjopen-2020-036858

- Prepublication history and additional materials for this paper is available online. To view these files, please visit the journal online (http://dx.doi. org/10.1136/bmjopen-2020036858).

Received 08 January 2020 Revised 02 January 2021 Accepted 05 January 2021

Check for updates

(c) Author(s) (or their employer(s)) 2021. Re-use permitted under CC BY-NC. No commercial re-use. See rights and permissions. Published by BMJ.

${ }^{1}$ School of Medicine and Health Management, Huazhong University of Science and Technology Tongji Medical College, Wuhan, China

${ }^{2}$ Jockey Club School of Public Health and Primary Care, Chinese University of Hong Kong, New Territories, China

Correspondence to

Professor Li Xiang;

xllyf@hust.edu.cn

\section{ABSTRACT}

Objective The objective of this study is to determine if critical illness insurance (CII) promotes the universal health coverage to reduce out-of-pocket (00P) medical expenditures and improve the effective reimbursement rate (ERR) in rural China.

Study design The 5-year monthly hospitalisation data, starting 2 years before the $\mathrm{CII}$ (ie, the 'intervention') began, were collected. Interrupted time series analysis models were used to evaluate the immediate and gradual effects of Cll on OOP payment and ERR.

Setting The study was conducted in Xiantao County, Hubei Province, China.

Participants A total of 511221 inpatients within 5 years were included in the analysis.

Results In 2016, 100288 patients received in-patient services, among which 4137 benefited from Cll. After the implementation of CII, 00P expenses increased $32.2 \%$ (95\% Cl $24.8 \%$ to $39.5 \%, p<0.001$ ). Compared with the preintervention periods, the trend changes decline at a rate of $0.7 \%$ per month after the implementation of Cll. Similarly, a significant decrease was observed in log ERR after the intervention started. The rate of level change is $16 \%$ change $(95 \% \mathrm{Cl}-20.0 \%$ to $-12.1 \%, \mathrm{p}<0.001)$. Conclusion Cll did not decrease the 00P payments of rural inpatients in 2011-2016 periods. The limited extents of population coverage and financing resources can be attributed to these results. Therefore, the Chinese government must urgently raise the funds of $\mathrm{Cll}$ and improve the Cll policy reimbursement rate.

\section{BACKGROUND}

Since the publication of The world health report 2010, universal health coverage (UHC) has received increasing attention from researchers in relevant fields. UHC is defined as financing systems that are specifically designed to provide people access to necessary health services with sufficient quality. These services must ensure that the user will not encounter financial hardship. ${ }^{1}$ In many low-income and middle-income countries, these conditions are not satisfied, and
Strengths and limitations of this study

- This study determines the effect of critical illness insurance (CII) on the reduction of pocket medical expenditures in rural China.

- The study identifies the abovementioned effects by using interrupted time series analysis model with 5year data.

- The study took Prais-Winsten regression to solve the autocorrelation.

- The study performed seasonal correction in accordance with periodic functions.

- The study was unable to identify a neighbouring county that did not implement CII with a similar level of economic status as a control group.

affordable and effective health services are not accessible to the entire population.

The lack of capacity to offer effective financial protection is the primary issue that hinders the achievement of UHC. In many countries, health financing relies on out-of-pocket (OOP) payments for services. ${ }^{2}$ These costs prevent people from seeking or continuing care; those who seek care incur catastrophic financial burdens that push them to poverty. ${ }^{3}{ }^{4}$ People who lack health insurance coverage or another form of financial protection hardly access health services, especially in-patient care, or experience delay in doing so. Therefore, providing financial protection to patients is necessary.

The Chinese government conformed rapidly and launched a series of rural health reforms. The first step in China's reforms involves the expansion of the social health insurance coverage. ${ }^{5}$ In 2003, China adopted the New Cooperative Medical Scheme (NCMS), a new health insurance system for rural areas where $80 \%$ of people do not have any kind of health insurance. ${ }^{6}$ In 2011, the 
NCMS expanded its coverage to include more counties, and $97 \%$ of the Chinese rural population was insured. This rate is higher compared with that in 2004, in which only 310 out of China's 2861 rural counties are covered by the scheme. ${ }^{78}$ However, a high coverage of health insurance does not necessarily provide a guarantee of UHC. Literatures indicated that the NCMS has no effect on reducing the OOP payment ${ }^{910}$ and even expands the gap of income-related inequity in rural China. ${ }^{11}$

In 30 August 2012, to further reduce the financial burden of rural patients, China established a supplementary insurance called critical illness insurance (CII), which aims to provide reimbursements of high medical expenses. In the early 1980s, CII is known as 'Dread Disease Insurance' in South Africa and began to flourish in USA, Canada and Australia. ${ }^{12}$ In USA and the UK, CII provides a single lump sum payment to the insured individuals, which includes medical and non-medical costs, such as mortgages and credits. ${ }^{13}$ In 2017, patients with critical illness get US $\$ 10000$ or US $\$ 20000$ as initial benefits from insurance companies in the USA. ${ }^{14}$ Today, CII covers have a considerable market share in Asian insurance markets. ${ }^{15}$

Many researches on CII were performed. A series of studies found that the extra premiums under the CII policies are extremely high, and the possible costs of adverse selection are related to the use of genetic test. ${ }^{16-18}$ Ozkok $^{19}$ used a Burr distribution to conduct the Bayesian modelling of the delay between the dates of diagnosis and settlement of claims in CII. Jindrová and VJRAiMMiAS used the same model to assess the event probability of CII. ${ }^{20}$ Recent studies reported the existence of healthcare disparities within CII. For instance, rich people receive more benefits from this policy than their counterparts. ${ }^{21}$ However, few studies evaluated the effect of CII, especially on health expenditures.

Unlike in other countries, the CII in China is an additional reimbursement for patients with higher payouts in NCMS. In other words, after claiming the CII via health insurance, all patients whose OOP payment still exceeds the premium, which is usually equal to the annual net income per capita of the rural residents, can obtain additional reimbursement. ${ }^{22}$ The average reimbursement rate is approximately $50 \%-70 \%$. The funding comes from NCMS, which means that roughly $5 \%$ of NCMS's total capital pool should be allotted to CII compensation. Given that the health system reform process aims to improve the UHC, policy-makers expect this scheme to reduce the OOP payments. The objective of the present study is to determine whether the CII relieves the individuals of the financial burden of healthcare by reducing such expenditures in rural China.

\section{METHODS}

Setting

Meng $e t a l^{23}$ reported that the lowest average in-patient reimbursement rates can be found in China's central region $(41.2 \%)$. Households in the central region suffer from high rates of catastrophic health spending. The rates of catastrophic health expenditure of households with members who were hospitalised are also high. ${ }^{24}$ In this study, we focus on the rural in-patient health expenditures in Xiantao County (XT), Hubei Province, which is one of the counties in the central region.

Hubei Province is located in central China and the middle reaches of Yangtze River. The gross domestic product (GDP) per capita of this province in 2016 was CNY55 665 (US\$8383), which ranks 11th among the 32 provinces (municipalities and autonomous regions) in China. XT is a city in Southwest Hubei that has a total area of $2538 \mathrm{~km}^{2}$. This county has jurisdiction in three streets and 15 towns. The total population of XT in 2016 was 1563500, and the GDP per capita is CNY56065 (US\$8438).

\section{Intervention}

The local government of Xiantao initiated a policy in May 2013 to improve the patients' financial access to medical care. The policy states that CII financing should allocate a certain percentage of funds from the NCMS. In 2013, NCMS financing included the contribution of individual rural residents (CNY60) and financial assistance of the government (CNY280) and the local government extracted CNY15 as the fund pool of CII.

We collected and compiled the local NCMS and CII policies from 2011 to 2016 . Table 1 denotes the policy changes in XT which was discussed in methods. Table 2 presents the percentage of population enrolled in the CII programme. Before the CII implementation, the deductible amounts for medical institutions inside and outside the county set by NCMS are CNY200 and CNY500, respectively. Therefore, the reimbursement rate of hospitals inside and outside Xiantao increased in varying degrees. However, because the limited pool of funds does not provide sufficient support, the local government reduced the reimbursement rate of NCMS while implementing CII. The reimbursement rate of the NCMS of hospitals in the county decreased from $80 \%$ to $60 \%$ after May 2013. The deductible amount of CII in 2014 was CNY8000, which increased to CNY12000 in 2016.

The rule of insurance reimbursement is to conduct NCMS before implementing CII. The government pays part of the reimbursement ratio prescribed by the policy, and the rest is paid by the patient. For example, consider a patient hospitalised in a county hospital in June 2013 with a total medical expense of CNY60 000. Assuming that all medical expenses are included in the benefit package, the NCMS can cover CNY35880 ((60000-200)×60\%). This amount is higher than the deductible amount in 2013 (CNY8000). Therefore, the patient will be further insured by CII. The CII will cover CNY12060 $((60000-35880-8000) \times 50 \%)$, and the patient's OOP expenses will be CNY20060 (60000-35880-12060). 
Table 1 Reimbursement policy for inpatient care in 2011-2016

\begin{tabular}{|c|c|c|c|c|}
\hline Policy & 2011 & 2012-2013 April & 2013 May-2015 December & $\begin{array}{l}2016 \text { January-2016 } \\
\text { December }\end{array}$ \\
\hline Insurance coverage & Only NCMS & & $\mathrm{NCMS}+\mathrm{Cll}$ & \\
\hline \multicolumn{5}{|l|}{ NCMS: } \\
\hline \multicolumn{5}{|l|}{ Deductible (CN¥) } \\
\hline In county* & 200 & 200 & 200 & 500 \\
\hline In county† & 75 & 80 & 60 & 70 \\
\hline Out county & 50 & 60 & 50 & 50 \\
\hline \multicolumn{5}{|l|}{ CII: } \\
\hline Deductible (CN¥) & Not available & Not available & 80000 & 12000 \\
\hline Reimbursement rate (\%) & & & over CN¥50000: 70\% & over CN¥100000: 70\% \\
\hline
\end{tabular}

${ }^{*}$ The local medical institutions contained primary hospitals and secondary hospitals, and none tertiary hospital. For primary hospitals, local NCMS did not set deductible (means 0 ), so the deductible in county was the deductible for local secondary hospitals.

†The reimbursement rate of local primary hospitals was $90 \%$, and did not changed for years. At the same time, the beneficiaries of Cll that we are concerned about are basically not using services in primary medical institutions, so the ERR in county mentioned here is also the local secondary hospitals.

CII, critical illness insurance; ERR, effective reimbursement rate; NCMS, New Cooperative Medical Scheme.

\section{Data source}

This study is based on the standardised administrative medical claims database of NCMS in XT, which includes all detailed medical treatments and insurance information of the rural residents in the jurisdiction. We collected all relevant data involving in patients from May 2011 to May 2016.

The OOP spending and effective reimbursement rate (ERR) are used to evaluate the effect of CII on the patients' financial burden. The OOP expenditures comprise the expenses below the deductible amount, expenses above the deductible amount copaid by the patients, and the non-reimbursable amount beyond the NCMS benefit packages. ${ }^{25}$ ERR is defined as the reimbursement amount divided by the total medical expenditure. $^{26}$ These definitions are consistently used by the
National Health and Family Planning Commission in China. The primary outcomes are the average OOP payment and ERR per month of all CII patients, whereas the secondary ones are the average OOP payment and ERR of patients who sought health utilisation insides and outside XT. For example, the OOP spending inside the county refers to the average health expenditures paid by the patients when they avail in-patient services in county hospitals.

\section{Statistical analysis}

In this study, we used interrupted time series analysis (ITSA) models, which are the strongest quasiexperimental method, to estimate the postpolicy changes in the level and trend of each outcome measure. ${ }^{27}$ After Gillings $e t a t^{28}$ introduced ITSA to the research on health

Table 2 The percentage of population enrolled in Cll programme

\begin{tabular}{llrrrrr}
\hline Variables & $\mathbf{2 0 1 1}$ & $\mathbf{2 0 1 2}$ & $\mathbf{2 0 1 3}$ & $\mathbf{2 0 1 4}$ & $\mathbf{2 0 1 5}$ & $\mathbf{2 0 1 6}$ \\
\hline Population & 1560800 & 1549900 & 1561200 & 1553700 & 1551400 & 1541600 \\
NCMS insured no (1) & 1145104 & 1196530 & 1217000 & 1223088 & 1132475 & 1099935 \\
Hospitalisation no (2) & 60489 & 87536 & 74502 & 87614 & 100792 & 100288 \\
Cll insured no (3) & - & - & - & 5308 & 4726 & 4137 \\
Cll insured percentage A (\%)=(3)/(1) & - & - & - & 6.434 & 0.417 \\
Cll insured percentage B (\%)=(3)/(2) & - & - & - & 4.689 & 4.125 \\
\hline
\end{tabular}

CII, critical illness insurance; NCMS, New Cooperative Medical Scheme. 
services, this approach has been widely used in assessing the effects of health services and policy interventions. ${ }^{29}$ Segmented regression analysis a powerful statistical method for estimating the intervention effects in interrupted time series studies. This method uses baseline trends and levels to project future monthly outcomes with the assumption that these values reflect what would have happened without the policy (ie, the counterfactual). The basic model includes terms that estimate the baseline level for each outcome (intercept), baseline trend (slope), change in the level of the outcome measured immediately after policy implementation and change in postpolicy trend.

Segmented regression (with methods to account for autocorrelation) is the most commonly used modelling technique in ITSAs. When only one group is under study (ie, no comparison groups), the regression model is expressed as

$$
Y_{t}=\beta_{0}+\beta_{1}(T)+\beta_{2}\left(X_{t}\right)+\beta_{3}\left(X T_{t}\right)
$$

where $Y_{t}$ is the outcome variable during a time period, which changes on a monthly basis between May 2011 and May 2016, $\mathrm{T}$ is the time since the start of the study (May 2011=1, June 2011=2, .., May 2016=61), and $X_{t}$ is a dummy (indicator) variable that represents the intervention. Preintervention periods are denoted as 0 ; otherwise, the value is 1 . In this study, the value of $X_{t}$ before May 2013 is 0 , whereas that after this period is $1 . X T_{t}$ is an interaction term, which is 0 before May 2013, and then increases by 1 each month from May 2013 ( 1 = May 2013, $2=$ June $2013,3=$ July $2013, \ldots)$. $\beta_{0}$ represents the intercept or starting level of the outcome variable before CII, $\beta_{1}$ is the slope or trajectory of the outcome variable until the introduction of CII, $\beta_{2}$ is the level change following the intervention, and $\beta_{3}$ indicates the slope change following the intervention. $X T_{t}$ is the interaction between time and intervention ). The CI of the $\mathrm{p}$ value was $95 \%$.

For time series data, seasonality is an issue need be concerned. If there is an uneven distribution of months before and after the intervention, such as a higher proportion of winter months, this could bias the results, especially in the analysis of short series. We confirmed the existence of seasonality through the timing chart and performed seasonal correction in accordance with the periodic functions used in similar research. ${ }^{30}$

Autocorrelation is another problem. Assumption of standard regression models is that observations are independent. This assumption is often violated in time series data because consecutive observations tend to be more similar to one another than those that are further apart, a phenomenon known as autocorrelation. Autocorrelation was assessed by examining the plot of residuals and the partial autocorrelation function and, where data are normally distributed, conducting tests such as Durbin-Watson (D-W) test. The D-W test suggested the existence of autocorrelations, which we corrected using the generalised least squares method (Prais-Winsten). ${ }^{31}$ We adopted the Dickey-Fuller statistic to determine the stability, and the results showed that the data constitute a stationary time series. The results of the KolmogorovSmirnov test indicated that the distribution of OOP payments is non-normal. Therefore, the logarithm of this value was used. According to Beard $e t a l^{32}$ when the input and output time series have been log-transformed using a natural log-transformation and the data made stationary we can interpret the coefficients in terms of elasticity, that is, a change of $1 \%$ from the overall mean value in the input series leads to a $\beta \%$ change from the overall mean in the output series. Log transforming the ERR outcomes was taken for coherence across the research. Given the large reimbursement differences between the hospitals inside and outside the county, the trend of the medical expenditure costs in these two subgroups were further analysed to examine the effects of CII. The raw data and stata command are provided in online supplemental files 1 and 2, and the CHEERS checklist is added in online supplemental file 3 ).

Wagner $e t a \hat{l}^{33}$ stated that the extreme values that do not fit in the series, which are referred to as wild data points, might occur in the time series. The result showed a decline in the OOP expenses in the county starting from January 2013, few months prior to the introduction of CII. The data points of the ERR in the same subgroup demonstrated a sharp increase after January 2013. The extreme change in both cases returned to relatively normal values after CII was introduced. The possible reason for this phenomenon is that the CII policy was issued at the beginning of the year, but the policy was implemented on May 2013. Therefore, the medical expenses incurred in the first 4 months of 2013 were not included. The lag between the periods when CII was announced and implemented may suggest people to visit primary hospitals and delay expensive procedures until they have coverage. To illustrate this modification, we represented the excluded points as hollow points to establish a contrast against the solid ones.

\section{Patient involvement}

Patients or the public were not involved in the conceptualisation or execution of this research.

\section{RESULTS}

In 2014, 87614 patients received in-patient services, among which $5308(6.058 \%)$ benefited from CII. This percentage decreased to $4.125 \%$ in 2016 .

Figure 1 and table 3 show that after the implementation of CII, OOP expenses increased $32.2 \%$ (95\% CI $24.8 \%$ to $39.5 \%, \mathrm{p}<0.001)$. Compared with the preintervention periods, the trend changes decline at a rate of $0.7 \%$ / month after the implementation of CII (95\% CI $-1.1 \%$ to $-0.2 \%, \mathrm{p}<0.001)$. The OOP spending of patients who were hospitalised in the county shows the same trend (figure 2). There is significant change of ERR in the regression slope is observed after the intervention started. The rate of level change is $16 \%$ change (95\% CI $-20.0 \%$ 

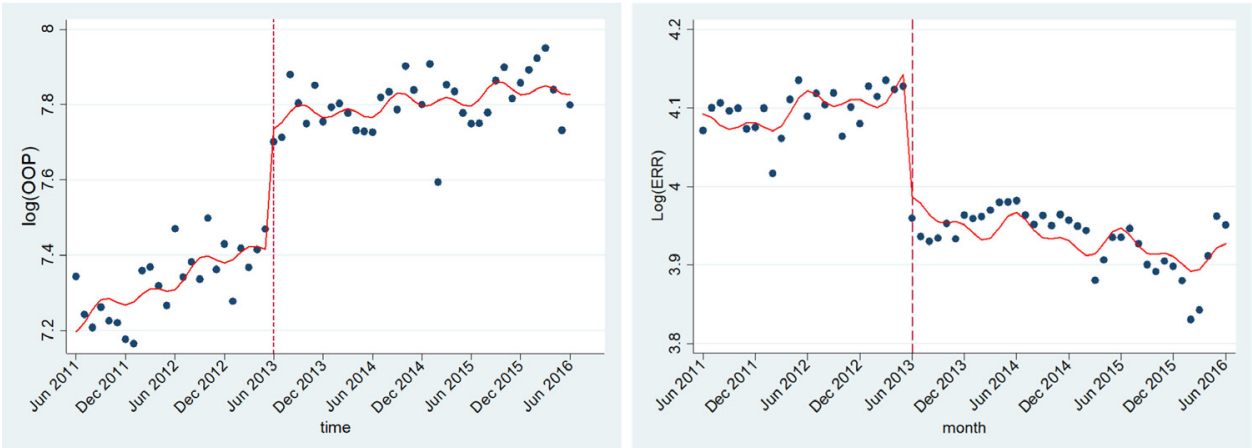

Figure 1 Segmented regression model showing OOP and ERR, May 2011-May 2016. ERR, effective reimbursement rate; OOP, out of pocket.

to $-12.1 \%, \mathrm{p}<0.001)$. The ERRs in the two subgroups decline after the implementation of the CII, but the ERR of the patients who sought healthcare in the county is more obvious at the time of intervention with $9.3 \%$ change $(95 \%$ CI $-14.2 \%$ to $-4.4 \%, \mathrm{p}<0.001)$. Figure 2 also shows that the trend changes of ERR of the patients hospitalised in the county declines after the announcement of CII. The adjusted R squared of segmented regression model of $\log$ OOP was 0.935 , which shows the fitness of this model was acceptable. The adjusted R squared, autocorrelation and partial autocorrelation plots of the model are presented in online supplemental file 4 .

The financing and use of CII funds in XT in 2014 and 2015 denote that the expenses exceed the amount raised in 2014 (CII funds $=255.2$ million, CII expenses=292.1 million). In 2015, the CII funds and expenses decrease.

\section{DISCUSSION}

The CII was designed to reduced OOP expenses and increase the ERR. Not only did it not do this, it may have had the opposite effect: a $32 \%$ increase in the OOP and a $16 \%$ reduction in the ERR. For the decline of ERR, local insurance policy probably should take primary responsibility. The increased ERR before the implementation of CII is due to the government's increasing investment on NCMS. The budget of the government for NCMS from May 2011 to May 2013 increased from CNY200 to
CNY280, ${ }^{34}$ which might attribute to the lower deductible amount and higher policy reimbursement rate. As a result, the ERR during this period increased. However, CII does not raise funds separately, but withdraws funds from the existing pool of NCMS total funds. The implementation of CII poses overspending risks towards NCMS funds. In 2014, CII used funds excessively and overpaid roughly $¥ 40$ million. In consideration of the overspending risk, the local government lowered the policy reimbursement rate of NCMS after May 2013, thereby resulting in a significant reduction in the ERR of all local patients after the implementation of CII. The purpose of basic health insurance is to protect all patients from the financial risks of diseases. CII aims to protect the economic risks of expensive treatments and vulnerable people and therefore should not crowd out the funds of NCMS to avoid decreasing the benefits of the patients, especially fragile ones.

The decreased ERR directly engage with the increase in OOP. For CII patients, lower reimbursement rate means they would get less benefit from insurance, and they had to pay more by themselves. Besides, this phenomenon can be attributed to two another reasons. First is the small number of rural patients who benefited from CII, which implies that the new insurance only reduces parts of the financial burden of the patients and does not affect the average OOP payments of all rural patients. The second reason is the limited average beneficiary of

Table 3 Interrupted time series analysis of outcome variables

\begin{tabular}{|c|c|c|}
\hline Outcome variables & $\beta_{2}$, level change after CII, $(95 \% \mathrm{Cl})$ & $\beta_{3}$, trend/slope change after Cll, $(95 \% \mathrm{Cl})$ \\
\hline Log (out-of-pocket payments) & $0.322^{\star \star *}(0.248$ to 0.395$)$ & $-0.007^{* *}(-0.011$ to to 0.002$)$ \\
\hline In county & $0.170^{\star \star}(0.056$ to 0.283$)$ & $0.004(-0.004$ to 0.104$)$ \\
\hline Out county & $-0.037(-0.270$ to 0.196$)$ & $-0.019^{*}(-0.033$ to to 0.004$)$ \\
\hline Log (effective reimbursement rate) & $-0.161^{\star \star \star}(-0.200$ to to 0.121$)$ & $-0.004^{* *}(-0.007$ to to 0.001$)$ \\
\hline In county & $-0.093^{\star \star \star}(-0.142$ to to 0.044$)$ & $-0.005^{\star \star}(-0.008$ to to 0.002$)$ \\
\hline Out county & $0.018(-0.031$ to 0.066$)$ & $-0.001(-0.004$ to 0.002$)$ \\
\hline
\end{tabular}

$\%$ changes results are multiplied by 100 .

${ }^{\star} \mathrm{P}<0.05,{ }^{* \star} \mathrm{p}<0.01,{ }^{* \star \star} \mathrm{p}<0.001$.

Cll, critical illness insurance. 

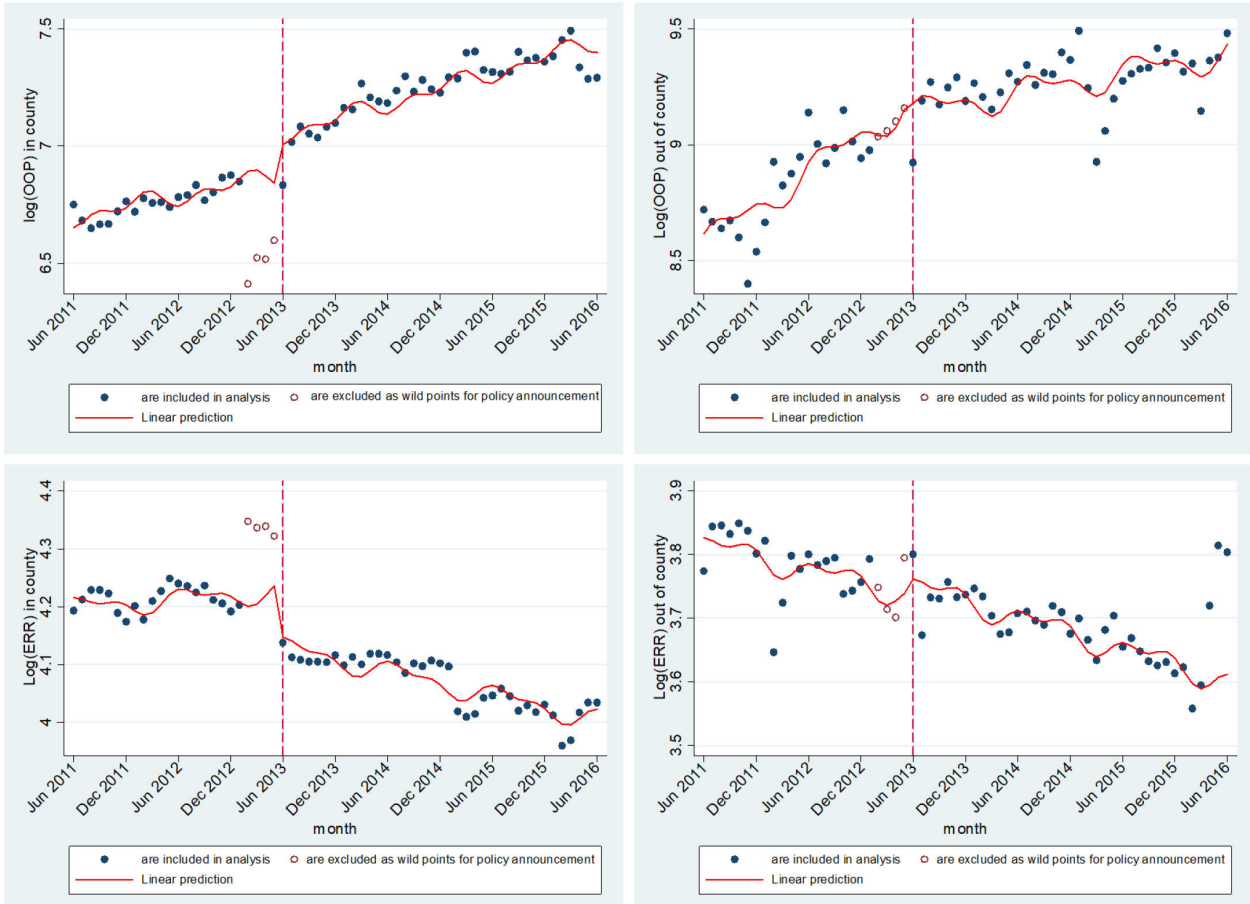

Figure 2 Segmented regression model showing OOP and ERR in and out of county, May 2011-May 2016. ERR, effective reimbursement rate; OOP, out of pocket.

the patients insured with CII. Nearly $10 \%$ of the total medical expenditure are paid by CII for the patients. The excessive deductible amount and limited reimbursement rate restrict the benefits of CII. In Xiantao, there were only $55 \%$ reimbursement ratio for medical expenditure during CNY12 000-CNY30 000. Only the patients who pay more than CNY100 000 can enjoy a $70 \%$ reimbursement rate. However, few patients reach this high level. The results clearly illustrate the drawback of CII when the OOP expenses rapidly increase.

These results are consistent with the findings of other studies. In a recent commentary, Yip and Hsiao claimed that the financial protection function of the current Chinese health system remains insufficient. According to the global health expenditure database of the WHO, the OOP payments in China account for $32 \%$ of the total health expenditure in 2014, which is higher than the level $(15 \%-20 \%)$ recommended by the WHO. ${ }^{35}$ Empirical evidences show that the high level of OOP payments in China results in severe health expenditure and medical impoverishment of the poor and disadvantaged. ${ }^{36}$

The trend of OOP payments inside and outside XT shows several differences. For patients who were hospitalised in county hospitals, the CII dramatically increases the OOP expenses at the intervention moment, which can be ascribed to the low policy reimbursement rate of NCMS. The average OOP expenses do not meet the deductible amount, and the economic burden reduction is dependent on the role of basic health insurance. Once the NCMS reimbursement rate decreases, the OOP spending increases. However, because hospitals outside the county have better and more expensive medical technology than county hospitals, the OOP expenditures of the patients who availed healthcare outside XT is relatively high ${ }^{37} 38$ (almost over CNY10000), and they are highly likely to benefit from CII. The increased reimbursement rate of CII neutralises the role of NCMS in reducing the reimbursement ratio, and thus slightly changes the trend of OOP payments. As a result, people who seek medical care outside the county benefit more from CII than patients in the county.

To expand the population coverage of CII and decrease the households' direct payments or co-payments for services, the government must improve the CII policy. The deductible amount should be settled not only in consideration of local medical expense distribution and disease characteristics, but also of the local average income. As presented in the annual government work report, the unified CII deductible line will be reduced, and the reimbursement rate will increase from $50 \%$ to $60 \%{ }^{39}$ The funds of CII, however, should be increased separately. The highest government announced that it will increase the per capita financial subsidy by CNY30 and allot half of this amount to CII.

\section{Strengths and limitations}

This study has several limitations. First, we are unable to find a neighbouring county who does not implement CII with a similar level of economic status as a control group. Finding such country will eliminate the mixed effects of other external influences. However, because this policy is implemented throughout the province, no suitable control group is identified. Meanwhile, the implementation pattern of CII among the provinces is quite different, 
and thus is not suitable as a control group. Second, because CII is an annual reimbursement, the amount is reimbursed once in the second half of the year in most cases. For the convenience of calculation, we disperse this amount in accordance with the proportion of medical expenses to each month, thereby disregarding the instantaneous effect of CII reimbursement. Lastly, because of the limitation of sample selection, the results of this study can only represent the regions with comparable sample GDP levels. The findings cannot reflect the results of economically developed eastern regions.

\section{CONCLUSION}

This study provides new evidence that CII did not effectively improve the UHC process in 2011-2016. The policy had limited extent of population and health service coverages and did not effectively decrease the OOP payments of inpatients. CII even decreased the ERR by spending the basic medical insurance fund pool. The results suggested that the Chinese government must urgently raise the funds of CII and improve the policy reimbursement rate.

Acknowledgements We would like to thank the staff of Health and Planning Commission of Xiantao County for their support on this research, as well as the associate editor and reviewers for their careful review and insightful comments, which helped us improve this manuscript.

Contributors In this paper, ZZ served as the principal investigator who was involved in the study design and conception, manuscript preparation and editing. LX provided helpful technical support to the study design. JJ was involved in the manuscript preparation and editing. LL helped in the data collection. SC performed the data analysis. All authors have read and approved the final manuscript.

Funding This study was supported by the project of the National Natural Science Foundation of China 'Study on the Dynamic Optimisation of Catastrophic Health Insurance Reimbursement Modes and the Scale of Fund Expenditure in the Perspective of UHC' (grant no. 71573095).

Disclaimer The funder provided us support to complete the voucher investigation and article writing.

Competing interests None declared.

Patient consent for publication Not required.

Ethics approval Ethical approval was obtained from the Institutional Ethics Committee, Huazhong University of Science and Technology, Wuhan, China (ethical approval number: IORG0003571). This study obtained written informed consent from all participants prior to the start of the survey.

Provenance and peer review Not commissioned; externally peer reviewed.

Data availability statement All data relevant to the study are included in the article or uploaded as online supplemental information.

Supplemental material This content has been supplied by the author(s). It has not been vetted by BMJ Publishing Group Limited (BMJ) and may not have been peer-reviewed. Any opinions or recommendations discussed are solely those of the author(s) and are not endorsed by BMJ. BMJ disclaims all liability and responsibility arising from any reliance placed on the content. Where the content includes any translated material, BMJ does not warrant the accuracy and reliability of the translations (including but not limited to local regulations, clinical guidelines, terminology, drug names and drug dosages), and is not responsible for any error and/or omissions arising from translation and adaptation or otherwise.

Open access This is an open access article distributed in accordance with the Creative Commons Attribution Non Commercial (CC BY-NC 4.0) license, which permits others to distribute, remix, adapt, build upon this work non-commercially, and license their derivative works on different terms, provided the original work is properly cited, appropriate credit is given, any changes made indicated, and the use is non-commercial. See: http://creativecommons.org/licenses/by-nc/4.0/.
ORCID iD

Junnan Jiang http://orcid.org/0000-0003-1932-7487

\section{REFERENCES}

1 Organization WH. World health report, 2010: health systems financing the path to universal coverage: World Health organization, 2010.

2 van Doorslaer E, O'Donnell O, Rannan-Eliya RP, et al. Effect of payments for health care on poverty estimates in 11 countries in Asia: an analysis of household survey data. Lancet 2006;368:1357-64

3 Xu K, Evans DB, Carrin G, et al. Protecting households from catastrophic health spending. Health Aff 2007;26:972-83.

4 Carrin G, Evans D, Xu K. Designing health financing policy towards universal coverage: SciELO public health 2007.

5 Meng Q, Fang H, Liu X, et al. Consolidating the social health insurance schemes in China: towards an equitable and efficient health system. Lancet 2015;386:1484-92.

6 Wagstaff A, Lindelow M, Jun G, Gao J, et al. Extending health insurance to the rural population: an impact evaluation of China's new cooperative medical scheme. J Health Econ 2009;28:1-19.

7 Lei X, Lin W. The new cooperative medical scheme in rural China: does more coverage mean more service and better health? Health Econ 2009;18 Suppl 2:S25-46.

8 You X, Kobayashi Y. The new cooperative medical scheme in China. Health Policy 2009;91:1-9.

9 Wagstaff A, Lindelow M, Jun G. Extending health insurance to the rural population: an impact evaluation of China's new cooperative medical scheme: The World Bank 2007.

10 Cheng L, Liu H, Zhang Y, et al. The impact of health insurance on health outcomes and spending of the elderly: evidence from China's new cooperative medical scheme. Health Econ 2015;24:672-91.

$11 \mathrm{Ma} \mathrm{J}, \mathrm{Xu}$ J, Zhang Z, et al. New cooperative medical scheme decreased financial burden but expanded the gap of income-related inequity: evidence from three provinces in rural China. Int $J$ Equity Health 2016;15:72.

12 Gatzert N, Maegebier A. Critical illness Insurances: challenges and opportunities for insurers. Risk Management and Insurance Review 2015;18:255-72.

13 Cummins JD, Venard B. International insurance markets: between global dynamics and local Contingencies-An introduction. Springer US, 2007.

14 Company MLI. What are accident and critical illness insurance? 200 Park Avenue, New York, NY 10166: Metropolitan Life Insurance Company, 2017[Available from:. https://www.d47.org/cms/lib/ IL01904560/Centricity/Domain/512/Accident_Critical\%20IIIness\% 20FAQ.pdf. (accessed November 18th, 2018).

15 Re G. Dread Disease-Studie Der gen re für 2000 bis 2004 - Wie Alles Anfing, 2007. Available: http://www.genre.com/sharedfile/pdf/ Themen15_Droste-de.pdf [Accessed 08/30/2012].

16 Macdonald AS, Waters HR, Wekwete CT. The genetics of breast and ovarian cancer II: a model of critical illness insurance. Scand Actuar J 2003;2003:28-50.

17 Gutiérrez C, Macdonald AS. Adult polycystic kidney disease and critical illness insurance. North American Actuarial Journal 2003;7:93-115.

18 Macdonald AJSAJ. Huntington's disease, critical illness insurance and life insurance 2004;2004:279-313.

19 Ozkok E, Streftaris G, Waters HR, et al. Bayesian modelling of the time delay between diagnosis and settlement for critical illness insurance using a Burr generalised-linear-type model. Insurance: Mathematics and Economics 2012;50:266-79.

20 Jindrová P, VJRAiMMiAS P. Bayesian probability models for critical illness insurance 2014:218-21.

21 Jiang J, Chen S, Xin Y, et al. Does the critical illness insurance reduce patients' financial burden and benefit the poor more: a comprehensive evaluation in rural area of China. J Med Econ 2019;22:455-63.

22 Government C. Guiding opinions on carrying out critical disease insurance work for urban and rural residents, 2012. Available: http:// www.gov.cn/gzdt/2012-08/31/content_2214223.htm

23 Meng Q, Xu L, Zhang Y, Qun M, Ling X, Yaoguang Z, et al. Trends in access to health services and financial protection in China between 2003 and 2011: a cross-sectional study. Lancet 2012;379:805-14.

24 Li Y, Wu Q, Xu L, et al. Factors affecting catastrophic health expenditure and impoverishment from medical expenses in China: policy implications of universal health insurance. Bull World Health Organ 2012;90:664-71. 
25 Xiang L, Pan Y, Hou S, et al. The impact of the new cooperative medical scheme on financial burden of tuberculosis patients: evidence from six counties in China. Infect Dis Poverty 2016;5:8.

$26 \mathrm{Yi} \mathrm{H}$, Zhang L, Singer K, et al. Health insurance and catastrophic illness: a report on the new cooperative medical system in rural China. Health Econ 2009;18 Suppl 2:S119-27.

27 Petrou P. An interrupted time-series analysis to assess impact of introduction of co-payment on emergency room visits in Cyprus. Appl Health Econ Health Policy 2015;13:515-23.

28 Gillings D, Makuc D, Siegel E. Analysis of interrupted time series mortality trends: an example to evaluate regionalized perinatal care. Am J Public Health 1981;71:38-46.

29 Zhang F, Wagner AK, Soumerai SB, et al. Methods for estimating confidence intervals in interrupted time series analyses of health interventions. J Clin Epidemiol 2009;62:143-8.

30 Bhaskaran K, Gasparrini A, Hajat S. Time series regression studies in environmental epidemiology 2013;42:1187-95.

31 Cliff A, Ord K. Testing for spatial autocorrelation among regression residuals. Geogr Anal 1972;4:267-84.
32 Beard E, Marsden J, Brown J. Understanding and using time series analyses in addiction research 2019;114:1866-84.

33 Wagner AK, Soumerai SB, Zhang F. Segmented regression analysis of interrupted time series studies in medication use research 2002;27:299-309.

34 County HaFPCoX. NCMS fundraising standard 2011.

35 WHO. Draft global health sector strategy on viral hepatitis, 20162021-the first of its kind, 2015.

36 Yip WC-M, Hsiao WC, Chen W, et al. Early appraisal of China's huge and complex health-care reforms. Lancet 2012;379:833-42.

37 Hou Z, Van de Poel E, Van Doorslaer E, et al. Effects of NCMS on access to care and financial protection in China. Health Econ 2014;23:917-34.

$38 \mathrm{Ye} \mathrm{C}$, Duan S, Wu Y, et al. A preliminary analysis of the effect of the new rural cooperative medical scheme on inpatient care at a County Hospital. BMC Health Serv Res 2013;13:519.

39 The annual government work report of 2019, 2019. Available: http:// www.gov.cn/zhuanti/2019qglh/2019lhzfgzbg/index.htm 